\title{
AVALIAÇÃo dA DEGRADAÇÃo do CORANTE VERMELHO BORDEAUX ATRAVÉS DE PROCESSO FOTOQUÍMICO
}

\section{ASSESSMENT OF RED DYE DEGRADATION THROUGH PHOTOCHEMICAL PROCESS}

\section{CRIStiano Pochmann Da SiLVA}

Graduando em Química Industrial. Bolsista de Iniciação Científica, UNIVATES

SANDRO MARMITT

Graduando em Química Industrial. Bolsista de Iniciação Científica, UNIVATES

\section{CLAUS HAETINGER}

Professor. Doutor do Programa de Pós - Graduação em Ambiente e Desenvolvimento da UNIVATES

\section{SIMONE STÜLP}

Professora. Doutora do Programa de Pós - Graduação em Ambiente e Desenvolvimento da UNIVATES, onde coordena o núcleo de eletroquímica e materiais poliméricos

\author{
Recebido: 22/11/06 Aceito: 03/02/08
}

\section{RESUMO}

Neste trabalho foi realizado o estudo da degradação fotoquímica do corante vermelho bordeaux. O estudo objetivou a avaliação de tratamentos alternativos com vistas à aplicação de tecnologias limpas. Os experimentos de fotodegradação foram realizados através da incidência de radiação UV em um compartimento contendo o corante (solução). O tratamento fotoquímico reduziu em $99 \%$ a coloração e a concentração da solução contendo o corante vermelho bordeaux.

PALAVRAS-CHAVE: Amaranto, corantes azo, corantes alimentícios.

\section{INTRODUÇÃO}

Os efluentes das indústrias alimentícias, devido às grandes concentrações de matéria orgânica e às suas usualmente fortes coloraçôes (Andrade, Souza \& Couto, 1998), são importantes fontes de poluição dos corpos d'água (Nadais, Capela \& Arroja, 2005), podendo provocar alterações na biota aquática, principalmente nas imediaçôes da descarga.Os rejeitos de indústrias alimentícias, além do forte caráter ácido ou básico, apresentam grande concentração de sólidos orgânicos em suspensão. Essa elevada carga orgânica provoca, em muitos casos, depleção do oxigênio dissolvido e modificaçốes na comunidade biológica (Andrade, Souza \& Couto, 1998). Além disso, a forte coloração acarreta alteraçōes na biota aquática dos leitos receptores desses resíduos.
Os tratamentos de efluentes industriais envolvem processos destinados à redução e à remoção de impurezas geradas na fabricação de produtos. Os métodos de tratamento estão diretamente associados ao tipo de efluente gerado, ao controle operacional da indústria e às características da água utilizada (Crespilho \& Rezende, 2004; Feng, Zhu \& Hou, 2006).

Dentre os vários processos podem-se destacar os tratamentos físico-químicos, caracterizados por métodos de separação de fases, a saber: sedimentação, decantação, filtração, centrifugação, coagulação e flotação dos resíduos. Vários dos processos utilizados no tratamento de efluentes industriais envolvem adição de insumos químicos, gerando, em muitos casos, lodo ao seu final. Existem, porém, processos alternativos (Crespilho, Santana \& Rezende, 2004; Nogueira \& Jardim,
1998; Pereira \& Freire, 2005; Tiburtius et al, 2005; Bertazzoli \& Pelegrini, 2002) a esses, tais como: Processos Oxidativos Avançados (POAs, por brevidade), fotólise direta e osmose reversa. Esses processos estão baseados, por exemplo, em tecnologias capazes de gerar espécies altamente oxidantes (Nogueira \& Jardim, 1998), em quantidade suficiente para provocar a mineralização/destruiçãa dos poluentes (solutos), dentre eles a matéria orgânica. Os POAs podem ser classificados em sistemas homogêneos ou heterogêneos, conforme a ausência ou a presença de catalisadores na forma sólida respectivamente, além de poderem estar ou não sob irradiação. Esses processos estão se tornando cada vez mais uma tecnologia limpa aplicável ao tratamento de águas residuárias, sendo necessária a adequação dos parâmetros experimentais ao tipo de efluente a ser tratado. $\mathrm{Na}$ fotó- 
lise direta com ultravioleta (UV) (Feng, Zhu \& Hou, 2006), a luz é a única fonte capaz de produzir a degradação (destruição) do poluente.

Os corantes azo $(\mathrm{N}=\mathrm{N})$ (Araújo, Yokoyama \& Teixeira, 2006) têm sido amplamente utilizados na indústria de alimentos para intensificar a coloração destes, tornando-os mais atrativos visualmente. O Ministério da Saúde, por meio da Agência Nacional de Vigilância Sanitária-ANVISA, permite a utilização de corantes artificiais em alimentos em quantidades controladas, devido à possibilidade de toxicidade destes produtos (Kapor et al, 2001).

Esses corantes possuem uma baixa degradabilidade frente aos métodos tradicionais utilizados em seus tratamentos, levando ao descarte de um efluente com alto índice de coloração. Por esse motivo este trabalho apresenta o estudo da degradação fotoquímica do corante vermelho bordeaux, composto por uma mistura dos corantes amaranto $(95 \%) \mathrm{e}$ azul brilhante FCF (5\%), objetivando a redução da coloração de soluções que o contenham. Na Figura 1 tem-se a estrutura do corante amaranto e a do corante azul brilhante.

\section{PARTE EXPERIMENTAL}

\section{Reagentes}

Nos ensaios de fotodegradação foi utilizado o corante alimentício comercial (indústria Duas Rodas - Santa Catarina - Brasil) vermelho bordeaux (bordeaux S ou Amaranto - Colour Index 16185 e Azul Brilhante (FCF) - Colour Index 42090), sem purificação prévia. As soluções aquosas do corante, em concentração de $100 \mathrm{mg} \cdot \mathrm{L}^{-1}$, foram preparadas utilizando-se água deionizada.

\section{Reator}

O reator usado na degradação fotoquímica (Figura 2) (Stülp, Silva, \& Marmitt, 2005) foi construído pela equipe do Núcleo de Eletroquímica e Materiais Poliméricos/UNIVATES (NEMP) e é formado por uma célula de acrílico de $6 \mathrm{~L}$ de dimensões $350 \mathrm{~mm} \mathrm{x}$ $160 \mathrm{~mm} \times 160 \mathrm{~mm}$, um tubo de quartzo (no interior do qual foi colocado o filamento de uma lâmpada) e uma bomba de recirculação submersa SARLO BETTER de vazão de 90 L.h. ${ }^{-1}$. Os ensaios foram realizados por meio de irradiação ultravioleta (UV) na solução contendo o corante, com duração de 5 horas. A irradiação foi feita com filamento de uma lâmpada de vapor de mercúrio de $250 \mathrm{~W}$ (Osram HQL), cuja cobertura original foi previamente removida (Figura 3).

\section{Análises}

A degradação fotoquímica foi acompanhada por espectrofotometria UV-visível (Perkin Elmer Lambda $25 \mathrm{UV} / \mathrm{Vis}$ Spectrometer) na faixa de comprimento de onda de 200 a 800 $\mathrm{nm}$. Todos os ensaios foram feitos em triplicata (Ribani et al, 2004). As medições de absorbância da solução contendo o corante foram realizadas a cada 30 minutos.

\section{RESULTADOS E DISCUSSÃO}

\section{Análises de ultravioleta - visível}

A Figura 4 apresenta o espectro de absorbância da solução contendo corante durante o processo de degradação fotoquímica por 5 horas. Neste espectro pode ser verificada a banda de absorção característica do corante amaranto $(\lambda=521 \mathrm{~nm})$ e do corante azul brilhante $(\lambda=630 \mathrm{~nm})$. A banda de absorção em regiões próximas a $260 \mathrm{~nm}$ indica a presença de carbono orgânico aromático (Souza \& Daniel, 2005). A degradação pode ser comprovada pelo decréscimo das bandas características ao longo do tempo.

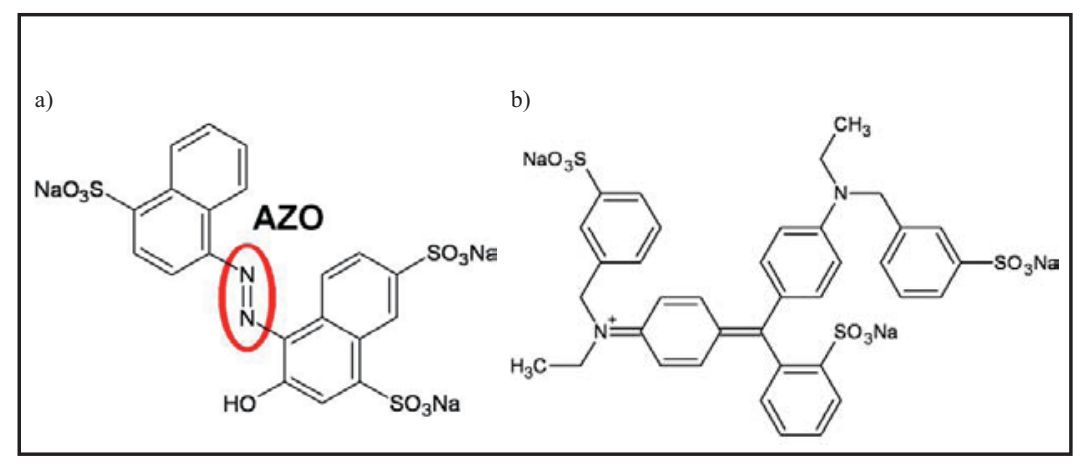

Figura I - Estrutura do corante amaranto (a) e do corante azul brilhante (b)

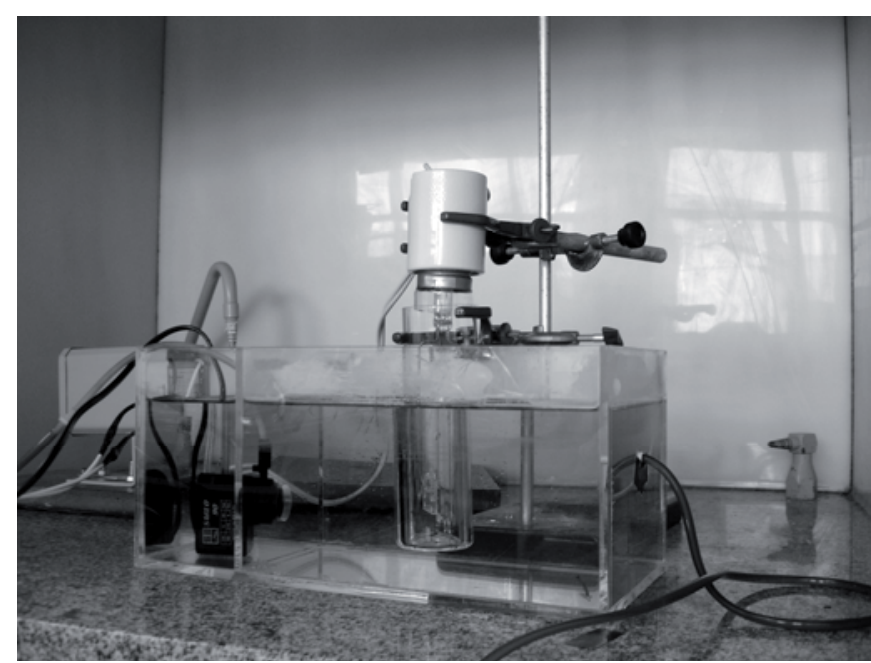

Figura 2 - Foto do reator para degradação de corantes pelo processo fotoquímico 
A partir da análise da redução de absorbância durante o processo (degradação) fotoquímico, verifica-se que houve redução de $99 \%$ da coloração da solução contendo o corante vermelho bordeaux (Figura 4).

A Figura 5 foi obtida a partir da avaliação da diminuição relativa $\mathrm{da}$ absorbância do corante em função do tempo em minutos $\left(\mathrm{Abs}_{\mathrm{t}} / \mathrm{Abs}_{0}\right.$ versus tempo), onde $\mathrm{Abs}_{0}$ representa a absorbância no instante $t=0$, enquanto que Abs indica a absorbância no instante t arbitrário.

Avaliando a Figura 5 pode-se verificar que ocorre decréscimo da concentração do corante no decorrer do tempo de degradação e que, a partir de 200 minutos, há a tendência de estabilização do sistema.

A cinética envolvida na redução de compostos orgânicos em soluçōes aquosas pode ser de primeira ordem ou ordem zero, dependendo se é baixa ou alta a sua concentração (C). Se há linearidade do gráfico $\mathrm{C}$ em função do tempo, então a cinética é de ordem zero. $\mathrm{Na}$ cinética de primeira ordem, o logaritmo natural da concentração dos reagentes deve diminuir linearmente com o tempo (Atkins, 1988). Usualmente o limiar de concentração (Bolton et al, 2001) alta ou baixa é $100 \mathrm{mg} . \mathrm{L}^{-1}$, sendo esta a concentração estudada neste trabalho. A Figura 5 indica um comportamento exponencial da concentração em função do tempo, dada a linha de tendência exponencial de primeira $\operatorname{ordem}(\mathrm{t})=1,02267 * \mathrm{e} \frac{-1}{53,07915} * \mathrm{i}$ com $\mathrm{R}^{2}=0,99401$, onde $\mathrm{R}$ indica o coeficiente de correlação. Logo a descoloração foi avaliada a partir da perspectiva de cinética de primeira ordem, o que pode ser comprovado pela Figura 6.

A avaliação foi feita a partir da construção de um gráfico $\ln ($ Abs /Abs $)$ em função do tempo (Atkins, 1988). Na Figura 6 tem-se o comportamento obtido experimentalmente, na qual se pode verificar que há um comportamento de primeira ordem. O resultado obtido com a degradaçã̃o do corante vermelho bordeaux é concordante com dados obtidos pela literatura (Araújo, Yokoyama \& Teixeira, 2006; Bolton et al, 2001; Catanho, Malpass \& Motheo, 2006). A equação da reta (linha de tendência linear) é $y(t)=0,23827-0,2251{ }^{*} t$, , com coeficiente de correlação $\mathrm{R}=0,99033$. $\mathrm{O}$ valor da constante de descoloração $(\mathrm{k})$ da reação (Atkins, 1988) de degradação

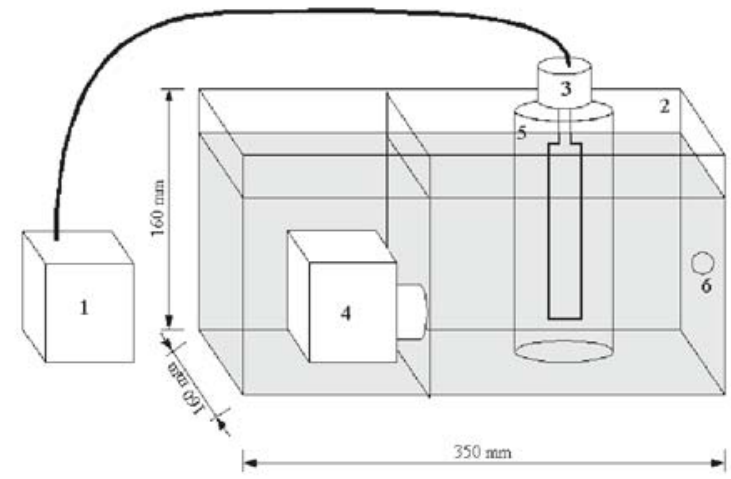

Figura 3 - Esquema do reator para degradação fotoquímica, cujos componentes são: (I) reator, (2) célula de acrílico, (3) lâmpada de vapor de mercúrio 250W, (4) bomba de recirculação (entrada da solução), (5) tubo de quartzo e (6) saída da solução

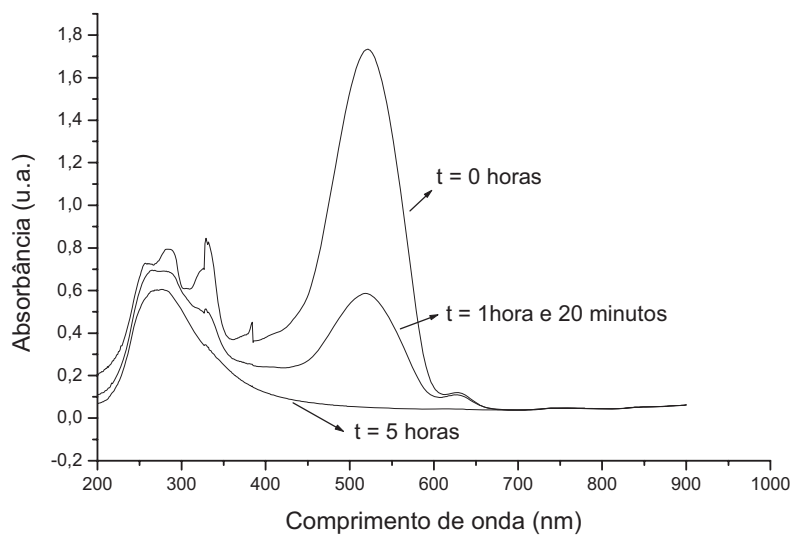

Figura 4 - Espectro UV/Vis do corante vermelho bordeaux, em diferentes tempos de degradação

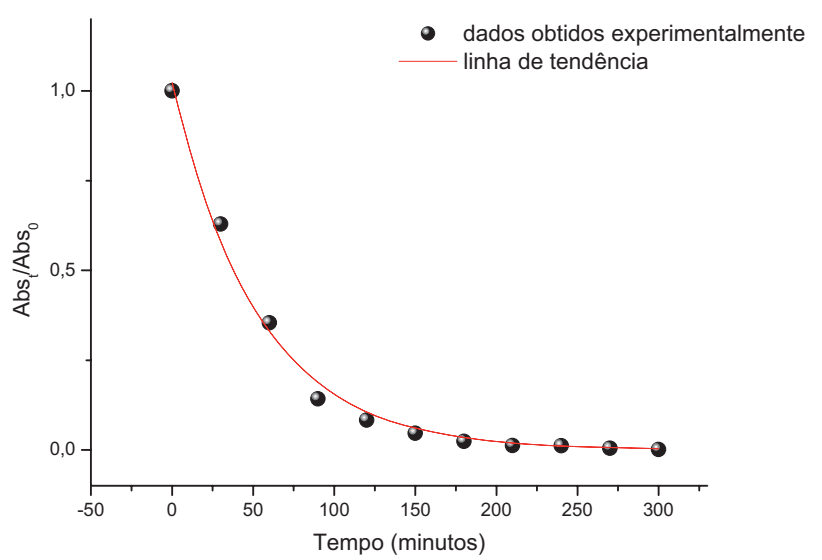

Figura 5 - Degradação do corante vermelho por processo fotoquímico 


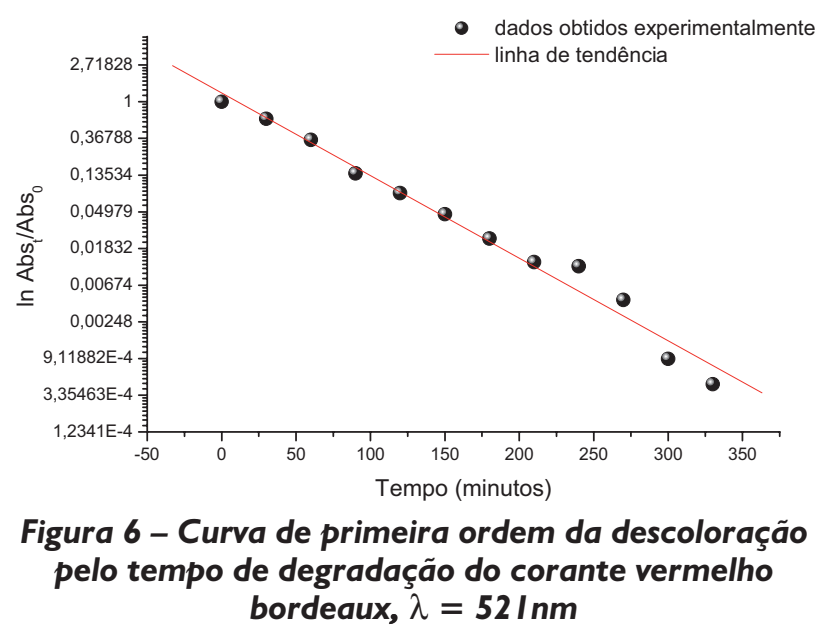

é igual a $0,02251 \mathrm{~min}^{-1}$, sendo este valor de k compatível com dados da literatura (Catanho, Malpass \& Motheo, 2006).

\section{Cálculo de eficiência do processo}

Para o cálculo de eficiência da degradação fotoquímica, podem ser utilizadas duas possibilidades de figuras de mérito, uma para altas concentraçôes de compostos orgânicos e outra para baixas concentrações.

O cálculo de eficiência (Bolton et al, 2001) (figura de mérito) considerando a condição de baixas concentraçôes de composto orgânico foi realizado por meio da avaliação da energia elétrica por ordem de magnitude por $\mathrm{m}^{3}\left(\mathrm{E}_{\mathrm{EO}}\right)$, de acordo com a seguinte Equação:

$\mathrm{E}_{\mathrm{EO}}=\frac{\mathrm{P} * \mathrm{t} * 1.000}{\mathrm{~V} * \log \left(\frac{\mathrm{C}_{\mathrm{i}}}{\mathrm{C}_{\mathrm{f}}}\right)}$

onde: $\mathrm{P}=$ potência da lâmpada em $\mathrm{kW}$, $\mathrm{t}=$ tempo em horas, $\mathrm{V}=$ volume em litros, $\mathrm{C}_{\mathrm{i}}=$ concentração inicial em mg. $\mathrm{L}^{-1}$ e $\mathrm{C}_{\mathrm{f}}=$ concentração final em mg. $\mathrm{L}^{-1}$.

O cálculo da concentração foi realizado a partir da curva de calibração do corante, obtida a partir dos valores de absorbância do mesmo em diferentes concentraçôes, com coeficiente de correlação $\mathrm{R}=0,99993$.

A partir do cálculo de $\mathrm{E}_{\mathrm{EO}}$, verificase que a eficiência do tratamento após 2,5 horas é de $52,0833 \mathrm{kWh} \cdot \mathrm{m}^{-3}$. Comparando este resultado com dados da literatura (Bolton et al, 2001; Catanho, Malpass \& Motheo, 2006), verifica-se que este valor está próximo dos valores obtidos aplicando-se tratamento fotoeletroquímico a outros corantes (corantes têxteis), que igualmente possuem grupo azo em suas estruturas.

\section{Adequação às leis ambientais}

Comparando-se os resultados obtidos com níveis de descarte permitidos por normativas e resoluções (Ministério do Meio Ambiente) destaca-se que, para corantes artificiais, estes devem estar virtualmente ausentes (Resolução CONAMA No 357/2005); o efluente não deve conferir mudança de coloração acentuada ao corpo receptor no ponto de lançamento.

\section{CONCLUSÕES}

Pelos resultados obtidos pode-se verificar a eficiência do processo fotoquímico no tratamento (degradação) do corante vermelho bordeaux, um corante de ampla utilização na indústria alimentícia. A aplicação do tratamento fotoquímico reduziu em $99 \%$ a coloração e a concentração da solução do referido corante, com consumo energético de $52,0833 \mathrm{kWh} \cdot \mathrm{m}^{-3}$. A degradação do processo seguiu um comportamento cinético de primeira ordem, comprovado tanto de forma experimental quanto matematicamente. Na continuidade do trabalho pretende-se estudar a degradação do efluente proveniente de resíduos de indústrias alimentícias que utilizam este corante.

\section{AGRADECIMENTOS}

Os autores agradecem ao Centro Universitário UNIVATES pelo suporte financeiro e à Fundação de Amparo à Pesquisa do Estado do Rio Grande do Sul (Fapergs $-\mathrm{n}^{\circ}$ do processo 0608250) pela bolsa concedida.

\section{REFERÊNCIAS}

ANDRADE, R.C.B.; SOUZA, M.F.L.; COUTO, E.C.G. Influência de Efluentes Têxteis e Alimentícios sobre o Metabolismo e Propriedades Físicas e Químicas do Rio Piauitinga (Sergipe), Química Nova, v. 21, p. $424-427,1998$.

ARAÚJO, F.V.F.; YOKOYAMA, L.; TEIXEIRA, L. A. C. Remoção de Cor em Soluçôes de Corantes Reativos por Oxidação Com $\mathrm{H}_{2} \mathrm{O}_{2} / U V$. Química Nova, v. 29, p. $11-14,2006$.

ATKINS, P.W. Physical Chemistry. Oxford, 3rd edn, 857 p. 1988.

BERTAZZOLI, R.; PELEGRINI, R. Descoloração e Degradação de Poluentes Orgânicos em Soluções Aquosas através do Processo Fotoeletroquímico, Química Nova, v. 25, p. 477 - 482, 2002.

BOLTON, J. R. et al. Figures-Of-Merit for the Technical Development and Application of Advanced Oxidation Technologies for Both Electric- and Solar-Driven Systems. Pure and Applied Chemistry, v. 73, p. $627-637,2001$.

CATANHO, M.; MALPASS, G. R. P.; MOTHEO, A. J. Avaliação dos Tratamentos Eletroquímico e Fotoeletroquímico na Degradação de Corantes Têxteis. Química Nova, v. 29, p. $983-989,2006$.

CRESPILHO, F. N.; REZENDE, M. O. O. Eletroflotação: Princípios e Aplicaçôes, Brasil, $1^{\text {a }}$ edn., 77 p. 2004.

CRESPILHO, F. N.; SANTANA, C. G.; REZENDE, M. O. O. Tratamento de Efluente da Indústria de Processamento de Coco utilizando Eletroflotação, Química Nova, v. 27, p. $387-392,2004$.

FENG, X.; ZHU, S.; HOU, H. Investigation Of $207 \mathrm{Nm}$ UV Radiation For Degradation Of Organic Dye In Water. Water S A, v. 32, p. $43-48,2006$.

http://www.mma.gov.br, acessada em Setembro 2006.

http://www.saude.gov.br, acessada em Setembro 2006.

KAPOR, M.A. et al. Eletroanálise de Corantes Alimentícios: Determinação de Índigo Carmim e Tartrazina. Eclética Química, v. 26, p. 53 - 68, 2001.

NADAIS, H.; CAPELA, I.; ARROJA, L. Treatment of Dairy Wastewater in UASB Reactors Inoculated with Flocculent Biomass. Water S A, v. 31 , p. $603-608,2005$.

NOGUEIRA, R. F. P.; JARDIM, W. F. A Fotocatálise Heterogênea e sua Aplicação Ambiental. Química Nova, v. 21, p. 69-72, 1998.

PEREIRA, W.S.; FREIRE, R.S. Ferro Zero: Uma Nova Abordagem para o Tratamento de Águas Contaminadas com Compostos Orgânicos Poluentes. Química Nova, v. 28, p. 130 - 136, 2005.

RIBANI, M. et al. Validação em métodos cromatográficos e eletroforéticos. Química Nova, v. 27, p. $771-780,2004$.

SOUZA, J.B.; DANIEL, L.A. Comparação entre Hipoclorito de Sódio e Ácido Peracético na Inativação de E. Coli, Colifagos E C. Perfringens em Água com Elevada Concentração de Matéria Orgânica. Engenharia Sanitária e Ambiental, v. 10, p. $111-117,2005$. 
STÜLP, S.; SILVA, C. P.; MARMITT, S. O Uso de Técnicas Eletroquímicas no Tratamento de Efluentes de Indústria Alimenticia: uma Ferramenta para a Gestão Ambiental. Estudo \& Debate, v. 12, p. $109-123,2005$.

TIBURTIUS, E.R.L. et al. Degradação de BTXs via Processos Oxidativos Avançados. Química Nova, v. 28, p. $61-64,2005$.

Endereço para correspondência:

Simone Stülp

Programa de Pós-Graduação

em Ambiente e Desenvolvimento

Centro Universitário UNIVATES

Rua Avelino Tallini, I7I

95900-000 Lajeado - RS - Brasil

E-mail: stulp@univates.br 